\title{
Quando o mundo se tornou um labirinto aberto*
}

\begin{abstract}
Márcio Silveira Lemgruber ${ }^{* *}$
Resumo: No presente artigo, busco apresentar, a partir do resgate da obra De rerum natura (Da natureza), do poeta/filósofo romano Tito Lucrécio Caro, a influência (e resistências) da filosofia epicurista na constituição do mundo e do homem moderno. Apresento traços dessa influência nas obras de Montaigne, Shakespeare, Giordano Bruno e Galileu Galilei, basilares para a construção da metáfora fundante do mundo como um labirinto aberto que começou a surgir (ou ressurgir).
\end{abstract}

Palavras-chave: Teoria da argumentação. Metáfora. Epicurismo. Lucrécio.

\section{Cuando el mundo se convirtió em um labirinto aberto}

\begin{abstract}
In the present article, by rescuing the work De rerumnatura (On the nature of things) written by Roman poet/philosopher Titus Lucretius Caro, I present the influence (and resistance) of epicurean philosophy in the concept of modern world and man. I introduce traces of the influence in the works of Montaigne, Shakespeare, Giordano Bruno, and Galileo Galilei, as the basis for the construction of the root metaphor of the world as an open labyrinth that started to emerge (or re-emerge).
\end{abstract}

Keywords: Theory of argumentation. Metaphor. Epicureanism. Lucretius.

\section{When the world became an opened labyrinth}

Resumen: En este trabajo se intenta presentar, a partir del rescate de DeRerum

\footnotetext{
* Texto adaptado de palestra proferida no II Seminário Internacional de Estudos Éticos e Retóricos em Educação, Rio de Janeiro, 2015.

** Doutor em Educação pela Universidade Federal do Rio de Janeiro (UFRJ). Professor adjunto do Programa de Pós-Graduação em Educação da Universidade Estácio de Sá. E-mail: mslemgruber@gmail.com
} 
Natura (de la naturaleza de las cosas), del poeta / filósofo romano Tito Lucrecio Caro, la influencia (y resistencias) de la filosofía epicúrea en la constitución del mundo y del hombre moderno. Presento trazas de influencia en las obras de Montaigne, Shakespeare, Giordano Bruno y Galileo Galilei, fundamentales para la construcción de la metáfora fundante del mundo como un laberinto abierto que comenzó a surgir (o resurgir).

Palabras clave: Teoría de la argumentación. Metáfora. Epicureísmo. Lucrecio.

\section{Introdução}

Um humanista florentino, numa tarde do inverno de 1417, desenrola mais um pergaminho e percebe haver tirado a sorte grande. Estava em suas mãos a cópia integral da obra De rerum natura (Da natureza das coisas), do poeta/filósofo romano Tito Lucrécio Caro, intocada havia séculos.

Poggio Bracciolini, ex-secretário do papa João XXIII - destituído e preso, dois anos antes, pelo Concílio de Constança - encontrava-se na biblioteca do mosteiro de Fulda, no sul da atual Alemanha, dedicado a seu esporte favorito: procurar por obras inéditas dos clássicos romanos. Isso era uma febre nos meios intelectuais renascentistas. Ele mesmo já tinha realizado grandes feitos, especialmente em relação a Quintiliano, de quem descobrira uma cópia quase completa de Institutio oratoria e o texto completo das Institutas, o manual de retórica e oratória mais importante da Roma antiga, conhecido apenas através de fragmentos.

Um breve parêntese, pois soa estranho a existência de um João XXIII na Idade Média, quando houve outro papa que adotou essa mesma denominação, mas já no século XX. Aliás, em O nome da rosa, romance passado no ano de 1327, Umberto Eco (1992) faz um personagem rogar uma praga contra o papa (Jacques de Cahors, intitulado João XXII), dizendo que deveria se passar muito tempo até que alguém tivesse a coragem de usar esse nome. Eco joga com o fato de saber (e saber que o leitor também o sabe) que somente em 1958 tal denominação seria 
adotada novamente. Mas, para entender como Angelo Roncalli pôde ter sido João XXIII, quando Baldassare Cossa já o fora, façamos uma rápida referência ao Concílio de Constança.

Nele, vários clérigos se atribuíam o direito ao papado. Cossa, o pretendente mais forte, já ocupava o Vaticano, como João XXIII. Tratava-se, sem dúvida, de uma figura polêmica. Ao mesmo tempo em que valorizava a cultura humanista e se fazia cercar de intelectuais, estimulava práticas um tanto condenáveis para auferir riquezas para a Igreja. Por exemplo, abreviou o intervalo entre os jubileus de indulgência plenária, peregrinações ao Vaticano que reduziam em milhares de anos os sofrimentos no Purgatório. Previstos inicialmente a cada 100 anos, seus intervalos tiveram decréscimos inversamente proporcionais ao crescimento da arrecadação. Para ampliar seus lucros, a Igreja oferecia promoções, tais como a validade das mesmas indulgências visitando santuários em outras regiões, desde que pagassem os custos da viagem a Roma.

Tais práticas geravam pesadas críticas dentro do próprio clero como as de Jan Huss, padre e reformador tcheco, que denunciava a venda de indulgências como extorsão e sustentava que os laicos podiam e deviam julgar seus líderes espirituais. Huss, que já havia sido excomungado em 1410, tinha um salvo-conduto garantindo-lhe a liberdade em Constança, mas logo foi preso. Cossa tentou desviar as denúncias que lhe eram feitas com a condenação e execução de Jan Huss. Mas a manobra diversionista não adiantou: pouco depois, o papa também foi condenado e perdeu o título João XXIII, que, assim, ficou disponível.

Voltando ao pergaminho, ressoar o poema perdido de Lucrécio foi como libertar o gênio preso na lâmpada. A existência da obra era de conhecimento dos círculos humanistas renascentistas que liam Cícero, Sêneca, Quintiliano e Ovídio. Mas, seria difícil suspeitar a dimensão do impacto que aquela voz, prestes a ser despertada, causaria na história da humanidade, ao ecoar em autores futuros. Mudaria o mundo: dois séculos depois, Galileu Galilei será poupado, pois a fogueira de Giordano Bruno chamuscara também a instituição que a acendeu. Mudaria também a 
visão de mundo: “apartam-se as muralhas do mundo”, que começa a se tornar um labirinto aberto, infinito.

No ensaio Da árvore ao labirinto, Umberto Eco enfatiza essa mudança de paradigma, com passagem da concepção de um fechado, finito, para o mundo labirinto aberto:

Mas o fato de que, da dogmática medieval da Arbor Porphyriana passando pelas últimas tentativas classificatórias do Renascimento, se tenha lentamente passado a uma concepção aberta do saber tem suas raízes na revolução copernicana. O modelo da árvore, concebido como repertório que se queria finito, espelhava a concepção de um cosmo ordenado e concluído em si mesmo, em seu próprio número definido e inalterável de esferas concêntricas. Com a revolução copernicana, a princípio a Terra se desloca para a periferia e estimula perspectivas cambiantes sobre o universo, depois as órbitas, de circulares que eram, se tornaram elípticas, pondo em crise outro critério de simetria perfeita, e por fim, primeiro na aurora do mundo moderno com a ideia de Nicolau de Cusa de um universo cujo centro está em toda parte e a circunferência em parte alguma, e depois com a visão bruniana da infinidade de mundos, o universo do saber se esforça por imitar a forma do universo planetário (ECO, 2013, p. 63).

Nesse trecho, chama a atenção que na abertura do mundo promovida pela modernidade, além do óbvio destaque do heliocentrismo copernicano, não haja referência ao materialismo atomista do epicurismo. Como veremos, ele terá importância capital nessa revolução epistemológica, embasando a unificação das físicas sub e supralunares, que tinham naturezas diferentes em Aristóteles. Como veremos também, essa separação fundamentava a teologia escolástica, servindo como avalista filosófico de dogmas religiosos.

Mas, a substituição de metáforas que fundamentam visões de mundo não é algo simples. Elas balizam a percepção da realidade. Por isso, o destaque que lhes é conferido entre as técnicas de persuasão elencadas na teoria da argumentação de Chaïm Perelman: 
É neste contexto que se pode falar de metáforas fundamentais, rootmetaphors. Que pretendem impor como verdadeira uma ontologia, uma visão de mundo. Todo o raciocínio filosófico ou teológico, em lugar de se iniciar por uma metáfora que no fim deve ser eliminada, tentará apresentar as razões que vão justificar a preferência conferida, em última análise, a determinada analogia em detrimento de outra. É nesse contexto que se deverá falar de "verdade metafórica”, aquela que exprime o real de maneira mais adequada (PERELMAN, 1987, p. 209-210).

Assim, é possível estudara história da filosofia destacando não somente a estrutura dos sistemas, mas, também, as analogias que lhes fundamentam a maneira como cada filósofo delas faz uso, adaptando-as ao seu ponto de vista. "Existe um material analógico que atravessa os séculos e que cada pensador usa do seu jeito” (PERELMAN, 1997, p. 345). Ou, como conjecturou Jorge Luis Borges (2005, p. 15), "talvez a história universal seja a história da vária entonação de algumas metáforas”.

Assim, atualmente, temos a emergência e consolidação de metáforas que enfatizam a ideia de trama, de multiplicidade - tais como teia (web), rede (net), labirinto, rizoma - em detrimento de concepções lineares de causalidade.

O pensamento não desconfia muito da metáfora, que se limita a desenvolver a expressão “o encadeamento das ideias”, mas cujo caráter analógico percebemos imediatamente se lhe opomos outra analogia. Opondo-me à concepção, a um só tempo dedutiva e unitária, do raciocínio em Descartes, e à sua visão do raciocínio como uma cadeia, escrevi num texto que analisava a estrutura do discurso argumentativo: "quando se trata da reconstituição do passado, o raciocínio se parece muito mais com um tecido cuja solidez é de longe superior à de cada fio que lhe constitui a trama” (PERELMAN, 1997, p. 339).

Mas, afinal, o que havia de tão radical no poema de Lucrécio para estimular uma mudança de metáfora fundante da própria visão de 
mundo? Um câmbio tão radical que justificaria expressão semelhante à de Sigmund Freud, diante da alegria das pessoas que recepcionavam a chegada da psicanálise aos Estados Unidos da América: “Mas eles não sabem que eu trago a peste?”.

Aqui, a peste seria causada por um vírus, incubado milenarmente, chamado epicurismo. De rerum natura (Da natureza das coisas ou, simplesmente, Da natureza) é um poema filosófico de Tito Lucrécio Caro, composto de 7.400 versos dividido em seis livros sem título. Não é um texto curto. Para dar uma ideia de sua extensão, ocupa 100 páginas de texto corrido, na edição original de Os Pensadores, que tem letra pequena e espaçamento estreito.

Lucrécio, que viveu em Roma de 96 a 55 a.C., era um admirador de Epicuro, filósofo grego (341 a 270 a.C.). Mais que discípulo, venerava-o: “Logo que tua doutrina, obra de um gênio divino, começa a proclamar a natureza das coisas, dispersam-se os terrores do ânimo, apartam-se as muralhas do mundo, e vejo como tudo se faz pelo espaço inteiro" (CARO, 1973, p. 71).

Epicuro costuma aparecer filiado a Demócrito, em manuais de Filosofia, na escola do atomismo. Essa categorização enfatiza o traço comum da concepção da natureza a partir de minúsculas partículas de tão pequenas, invisíveis e indivisíveis: os átomos, a matéria de que é feito o Cosmo, a Terra, o Homem. Mas, para além desta aproximação, o atomismo de Epicuro se distancia e conflita com o de Demócrito, como bem percebeu Karl Marx, em sua tese de doutorado sobre os dois filósofos. É o que sustenta também José Americo Pessanha:

Esse processo cosmogônico sem télos, sem finalismo, sem princípio regedor e intencional (...) a construção sem arquiteto, a gênese materialista e perene dos mundos, efetivada sem interferência de qualquer arbítrio ou insondável desígnio, portanto sem mistério: à dimensão da inteligibilidade humana. Epicuro a adota. Mas a altera fundamentalmente, nela introduzindo dois conceitos decisivos, que permitem fazer da física a sustentação de sua ética hedonista: os conceitos de peso e desvio (PESSANHA, 2015, p. 11). 
O desvio (clinamen, para Lucrécio) é central na física epicurista, pois possibilita as colisões que engancham os átomos, engendrando, por tentativas infinitas, todas as coisas que existem. Aqui entra seu não determinismo.

Se não pudessem desviar-se, todos eles, como gotas de chuva, cairiam pelo profundo espaço sempre de cima para baixo e não haveria para os elementos nenhuma possibilidade de colisão ou de choque; se assim fosse, jamais a natureza teria criado coisa alguma (CARO, 1973, p. 58).

Para o atomismo de Epicuro e Lucrécio, a natureza não é, a natureza está sendo. E ela se faz sem um roteiro já dado, o acaso acontece como transgressão a regularidades. Há ordem no cosmo, mas essa ordem não impede a ocorrência de novas singularidades.

Mas, depois de terem sido mudados de mil modos diferentes através de toda a imensidade, depois de terem sofrido pelos tempos eternos toda espécie de choques, depois de terem experimentado todos os movimentos e combinações possíveis, chegaram finalmente a disposições tais que foi possível o constituir-se tudo o que existe (CARO, 1973, p. 52).

Mesmo com o cuidado de não transpor seus conceitos para a ciência contemporânea - já se disse que o átomo epicurista se parece mais com o que hoje entendemos por molécula - podemos apontar influências, pistas que levaram à concepção de teorias como o evolucionismo. A ideia de que a natureza experimente incessantemente influenciou Charles Darwin, através de seu avô, Erasmus, estudioso de Lucrécio. Por sua vez, Einstein reconhecia que "a especulação filosófica dos atomistas da antiguidade tinha preparado o terreno para as provas empíricas de que o atomismo moderno depende” (GREENBLATT, 2012, p. 219). 
Com o desvio - o clinamen - a física epicurista deu sua maior contribuição para a história da ciência: a passagem do possível ao real se faz por transgressões das leis mecânicas. Violações da perfeição geométrica, as assimetrias que movem a natureza só puderam ser percebidas quando os filósofos da natureza e os cientistas se libertaram de padrões mentais que não os deixavam vê-las. A constatação de que, num Universo perfeitamente simétrico e equilibrado, o excesso de matéria não seria gerado - e nós não estaríamos aqui - perpassa o livro Criação (im)perfeita, do físico Marcelo Gleiser:

Uma das grandes surpresas (da física das partículas, no século XX, com suas mudanças de identidade, espontaneamente) foi a descoberta de que algumas das simetrias são violadas, e que essas violações têm consequências profundas não só para a compreensão dos processos que ocorrem no mundo subatômico, mas também para a nossa existência (GLEISER, 2010, p. 161).

O próprio Pasteur fez uma descoberta decisiva, que mudou nossa compreensão de como a vida pode ter surgido da não vida, ao mostrar que a vida só é possível quando construída a partir de pedaços assimétricos: L’Univers est dissymétrique! (GLEISER, 2010, p. 263).

Assim, a filosofia epicurista é, ela própria, um clinamen que legou aos tempos futuros muitas linhas de especulação a serem desenvolvidas, como a especulação de mundos infinitos, portanto, sem um centro, e muito menos a Terra no centro do universo.

Ora, se há tão grande quantidade de elementos que não bastaria para os enumerar a vida inteira dos seres vivos, e subsistem a mesma força e a mesma natureza que podem, em todos os lugares, reuni-los do mesmo modo por que foram reunidos neste mundo, é força confessares que há noutros pontos outras terras e várias raças de homens e várias gerações de bichos bravos. (...) Por isso se tem de aceitar que, de igual maneira, que não somos únicos nem a Terra, nem o Sol, nem a Lua nem o mar e nem tudo o mais que existe (CARO, 1973, p. 68). 
Que poder essas palavras, mais de mil e quinhentos anos depois, teriam sobre a mente de Giordano Bruno. Podemos imaginá-lo, em Londres, discutindo Da natureza com seu amigo John Florio, filho de refugiados religiosos italianos. E também sobre Galileu Galilei que, a cada telescópio mais potente que construía, via mais longe, percebendo que as fronteiras do mundo se apartavam. O mesmo se dará também em relação ao infinitamente pequeno, desde os primeiros microscópios até os gigantescos aceleradores de partícula contemporâneos.

Além de descentrar a Terra, De rerum natura descentra também o ser humano. Outro ponto muito ousado e de grande atualidade é a afirmação de que somos feitos do mesmo material que os animais e todas as coisas. O ser humano não está na natureza, ele é natureza. As partículas invisíveis que constituem tanto o mundo inorgânico quanto o orgânico, inclusive os humanos, não são sensíveis e não provêm de alguma fonte misteriosa. Somos feitos dos mesmos átomos de que tudo mais se faz. Ainda nos referiremos à influência dessas palavras sobre Michel de Montaigne, em seu tema favorito: debochar da arrogância humana.

Para Epicuro e Lucrécio, o materialismo atomista não exila do cosmo os deuses, mas a providência divina. Os deuses existem, mas têm mais o que fazer (se dedicam, sobretudo, a exercitar sua sabedoria) do que ficar cuidando das demandas dos humanos. A consequência dessa concepção teológica é a denúncia dos malefícios causados pelas religiões, que infundem o temor nos homens:

De fato, o terror oprime todos os mortais, apenas porque veem operar-se no céu e na terra muitas coisas de que não podem de nenhum modo compreender a causa, e cuja origem atribuem a um poder dos deuses (CARO, 1973, p. 41).

Seu grande mérito foi a construção de um materialismo não determinista. O desvio - a possibilidade do acaso na natureza - vai ser a base para o livre arbítrio na esfera humana. Dessa forma, o clinamen será o 
fundamento também da ética epicurista, que responsabiliza o homem por seus atos, suas escolhas. Cabe aqui citar mais uma vez José Américo Pessanha, em seu belo texto As delícias do jardim:

Ao corrigir os fundamentos da física de Demócrito, Epicuro torna viável o que em seu antecessor permanece como paradoxo, basear a normatividade ética, que sempre pressupõe a liberdade (para dirigir a vida nessa e não noutra direção, para viver desse e não daquele modo), numa física determinista. O clinamen introduz no mecanismo determinista o espaço para o processo de libertação interior, que a ética epicurista prescreve: a liberdade é desviante, introduz nova direção a partir da reta (in)flexível da fatalidade (PESSANHA, 2015, p. 12).

Epicuro deixou bem claro o que entendia por busca do prazer, num dos raros textos seus que chegou a nós: a carta a seu discípulo Meneceu, conhecida como Carta sobre a felicidade.

Quando então dizemos que o fim último é o prazer, não nos referimos aos prazeres dos intemperantes ou aos que consistem no gozo dos sentidos, como acreditam certas pessoas que ignoram o nosso pensamento, ou não concordam com ele, ou o interpretam erroneamente, mas ao prazer que é ausência de sofrimentos físicos ou de perturbações da alma. (...) Não são, pois, bebidas nem banquetes contínuos, nem a posse de mulheres e rapazes, nem o sabor dos peixes ou das outras iguarias de uma mesa farta que tornam doce uma vida, mas um exame cuidadoso que investigue as causas de toda escolha e de toda rejeição e que remova as opiniões falsas em virtude das quais uma imensa perturbação toma conta dos espíritos (EPICURO, 2002, p. 43-45).

Por sua vez, Lucrécio afirma a superioridade da vida primitiva. Essa tese, como sabemos, terá grande repercussão. Nos remete ao ideal do “bom selvagem” de Rousseau e marcará fortemente o movimento estético do romantismo. Mas, muito antes do filósofo de Genebra, ainda no século XVI, Américo Vespúcio, a partir de suas leituras dos clássicos romanos 
em Florença, chamou os indígenas do Novo Mundo de epicuristas. É o mesmo sentido deste curioso trecho dos Ensaios de Montaigne:

Dizem que no Brasil as pessoas só morrem de velhice, o que se atribui à pureza e à calma do ar que respiram, e que, a meu ver, provém antes da serenidade e da tranquilidade de suas almas isentas de paixões, de desgostos, de preocupações que excitam e contrariam. Ignorantes, iletrados, sem lei nem rei, nem religião alguma, sua vida desenvolve-se numa admirável simplicidade (MONTAIGNE, 1996, p. 412).

Na hierarquia de valores de Epicuro (1973, p. 28), o bem maior não estava num ser ou numa dimensão transcendente: "De todas as coisas que nos oferece a sabedoria para a felicidade de toda a vida, a maior é a aquisição da amizade.” Sua tão famosa (e difamada) comunidade intelectual - o "jardim das delícias" - era uma horta para abastecer suas refeições frugais. Ali, a philia ganhou uma dimensão inusitada para a época. Ao invés de abranger tão somente a aristocracia, seu jardim acolhia igualmente os excluídos da cidadania ateniense: mulheres, estrangeiros, escravos. Ele ilustra bem um tempo - após o declínio dos deuses e antes da chegada do Cristo -em que, segundo Flaubert, só o homem existiu.

Mas, para mudar uma visão de mundo, não bastava apontar o telescópio para o céu e enxergar. Era preciso poder ver o que se enxergava. Para se apartar as muralhas do mundo, estilhaçando as esferas cristalinas que o conformavam, tinha-se que apartar também as muralhas da mente. E não era pouco, era necessário romper com a ideia do cosmo como cenário da Terra, habitat do homem, ser em contato com o Criador, que planejou e gerencia o universo. Contudo, filósofos da natureza como Bruno e Galileu puderam fazê-lo, concebendo mundos infinitos, constituídos de átomos invisíveis, em grande parte pela herança de pensadores pagãos da antiguidade clássica.

O legado literário/filosófico do paganismo fascinava e assustava a intelectualidade, sobretudo os membros do clero, que também (e em muito) a integravam. A teologia medieval investiu sempre na tarefa de 
domesticar a filosofia greco-romana, com Santo Agostinho cristianizando Platão e com São Tomás de Aquino, por seu turno, o fazendo com Aristóteles. Ainda que filósofos pagãos, em suas metafísicas havia lugar - “o mundo das ideias”, “o bem”, “a causa primeira” - passível de ser ocupado pelo Deus do cristianismo. Adaptadas, elas serviam como imbatíveis argumentos de autoridade, especialmente a de Aristóteles, o filósofo. Por isso, a tentativa de contestar aspectos de sua física poderia ser acusada de heresia, pois sua negação comprometeria o aval para embasar dogmas, como o da transubstanciação, na Eucaristia. Ao usar o telescópio e ver as imperfeições no céu, Galileu desmoronou a milenar separação aristotélica entre as físicas sublunar e supra lunar. Foi a entrada da Terra no mundo labirinto aberto, que não tem “espaço vip” reservado à perfeição. Em muitas mitologias religiosas, os humanos originalmente o ocupavam, mas cometeram erros, sendo condenados à expulsão e a carregar a culpa por todo o sempre.

Mas, havia paganismos e paganismos. Outros não eram passíveis de adaptação ao cristianismo. Era o caso de Epicuro e Lucrécio, com seu mundo, ou melhor, seus infinitos mundos, sem providência divina a concebê-los e velá-los e de quem somos devedores. E a alma morre! Autores assim, quando muito, podiam ser tolerados, colocados no rol dos que podiam ser lidos, desde que como fábulas.

A desconstrução de Epicuro e Lucrécio foi realizada por adversários teológicos e/ou filosóficos, ao longo de séculos. Desqualificar a pessoa, comprometendo com isso seu argumento: Epicuro, o devasso; Lucrécio, o louco, tão somente. Delenda epicurismo.

Cícero, inimigo do epicurismo, referiu-se à comunidade do filósofo como "um jardim de prazer onde os discípulos enlanguesciam em gozos refinados”. Já São Jerônimo, não se sabe de onde, afirmou sobre Lucrécio - e virou verdade - que "depois que uma poção do amor o deixou louco, e ele escreveu, nos intervalos de sua insanidade, diversos livros que Cícero revisou, ele se matou por suas próprias mãos no quadragésimo quarto ano de sua vida.” 
O padre, médico e escritor François Rabelais ilustra e reforça, em sua vida e obra, o epíteto de epicurista, para o bem e para o mal. Por um lado, é visto como epicurista nas desmedidas gastronômicas e etílicas dos gigantes de suas aventuras, no exagero das caricaturas, na escatologia com que critica adversários, em geral do alto clero. É curioso notar que a apresentação da edição brasileira de Gargântua e Pantagruel (RABELAIS, 2009) termine indagando se Rabelais foi um religioso que busca as origens puras de sua fé, ou então um epicurista aproveitador, travestido de humanista. Temos que reconhecer que a desconstrução foi eficaz. Por outro lado, a vida de Rabelais nos mostra a dificuldade que teve para poder estudar a língua grega, com as constantes censuras e confiscos de livros pelas ordens religiosas a que foi filiado, pois o grego era a senha para acesso à filosofia do paganismo ameaçador. Rabelais, que assume o epicurismo como norma de vida, mescla como ninguém grosseria e erudição refinada na crítica aos costumes de sua época. Quanto à educação, conclui sobre a extensa memorização de obras, ao longo de muitos anos: Gargântua saiu tão sábio quanto já era antes.

Epicurista, via Lucrécio, até a medula óssea foi mesmo Michel de Montaigne. Na torre de seu castelo, perto de Bordeaux, um dos livros mais consultados durante os anos em que escreveu os Ensaios foi justamente De rerum natura, de que tinha a edição de 1563, de Denys Lambin, que apresentava como "licença poética" as contestações à providência divina e à imortalidade da alma. O exemplar pessoal de Montaigne foi identificado recentemente em um leilão de obras antigas. Todo anotado e comentado, serviu de base para dezenas de referências a Lucrécio, ao longo dos Ensaios.

Uma forte influência ali presente diz respeito ao descentramento do homem como razão de ser do universo e a consequente aproximação com os demais animais: "disse tudo isso para estabelecer a semelhança que há entre os seres da criação e recolocar-nos entre as demais criaturas. Não estamos acima nem abaixo delas. Tudo o que existe sob os céus está sujeito à mesma lei e às mesmas condições” (MONTAIGNE, 1996, p. 
386). Colocações como esta gerariam, no século seguinte, denúncias do influente bispo Bossuet que levariam os Ensaios para o Index dos livros proibidos pela Igreja católica.

Quando aborda questões relativas ao conhecimento humano, suas possibilidades e limitações, Montaigne tira partido do lugar, da postura com que pensa e escreve. Ele não está comprometido com a defesa de um sistema, como não deixar ruir a física aristotélica ou a cosmologia geocêntrica. Assim, percebe que o normal é que as explicações astronômicas tenham sua vida útil e sejam um dia superadas:

O céu e as estrelas foram durante três mil anos considerados em movimento. Todos acreditaram, até que Cleantes de Samos ou, segundo Teofrasto, Nicetas de Siracusa, se lembrou de sustentar que a terra é que girava em torno de seu eixo, seguindo o círculo oblíquo do zodíaco; e em nosso tempo Copérnico demonstrou tão bem esse princípio, que dele se vale em seus cálculos astronômicos. Que concluir, senão que não temos que nos preocupar com saber qual dos sistemas é o verdadeiro? Quem sabe daqui a mil anos outro sistema não os destruirá a ambos? (MONTAIGNE, 1996, p. 477).

Tais considerações se aplicam também às explicações geográficas, as que demarcam as fronteiras do que conhecemos do planeta que habitamos:

Ptolomeu, que foi personagem de realce, determinara os limites de nosso mundo; os filósofos antigos pensavam nada ignorar a esse respeito acerca do que existia, salvo algumas ilhas longínquas que podiam ter escapado às suas investigações; e, há mil anos, fora agir como os pirrônicos pôr em dúvida o que então ensinava a cosmografia e as opiniões aceitas por todos; referir-se à existência de antípodas era heresia. E eis que nesse século se descobre um continente de enorme extensão, não uma ilha, mas uma região quase igual em superfície às que conhecíamos. Os geógrafos de nosso tempo não deixam de afirmar que agora tudo é conhecido: "pois nos comprazemos com o que temos, o que nos parece superior ao resto" (Lucrécio). Pergunto então se, visto que Ptolomeu se enganou outrora acerca do que constituía 
o ponto de partida de seu raciocínio, não seria tolice acreditar hoje resolutamente nas ideias de seus sucessores, e se não é provável que esse grande corpo denominado "mundo" seja bem diferente do que julgamos? (MONTAIGNE, 1996, p. 478).

Também o homem vai se tornando um labirinto. Montaigne é um legítimo representante do ceticismo que inaugura o homem moderno. Ele se sabe cindido, ambíguo, e assim, ao contrário do que normalmente ocorre em textos do gênero memórias ou confissões, não promete ao leitor mostrar seu eu verdadeiro, pois este não tem nem para si mesmo. Assume o desafio de escrever sobre si mesmo, de conhecer o mundo através do fragmento que é o ser humano.

Eu que me analiso, a fundo, e tenho os olhos sempre voltados para mim mesmo, como quem não tem muito o que fazer alhures (...) mal ouso dizer as falhas e fraquezas que percebo em mim(...) Nos meus próprios escritos nem sempre redescubro o meu pensamento, não sei mais o que desejei exprimir e não raro me esforço por corrigi-lo, modificá-lo, pois o significado primeiro, por certo mais interessante, me escapa. Não faço senão ir e vir. Meu julgamento não segue uma linha reta, flutua ao léu... (MONTAIGNE, 1996, p. 473).

Como uma mensagem que vai sendo passada por tambores, essas ideias vão se multiplicando. Escritas num castelo no sul da França atravessam o canal da Mancha e são traduzidas para o inglês pelo já referido John Florio, o descendente de italianos, amigo de Giordano Bruno, durante sua estadia londrina. Florio era professor de francês e italiano de um autor que começava a fazer muito sucesso em Londres, chamado William Shakespeare, a quem apresentou os Ensaios. Este seria um dos livros mais lidos e influentes sobre sua obra. Um de seus textos mais famosos, Hamlet, ilustra bem a incorporação do individualismo ceticista. Lembro-me da saudosa crítica teatral Barbara Heliodora afirmar que se Hamlet fosse ainda um homem medieval, a peça duraria apenas uns 
poucos minutos: veria o fantasma do pai clamando por justiça, automaticamente executaria a vingança. Porém, Hamlet - homem moderno - pensa, pondera, hesita, passa a tradição pelo crivo da desconfiança. Estabelece uma longa deliberação consigo mesmo (que é o principal da trama) e a peça dura em torno de 4 horas.

Montaigne e Shakespeare têm traços comuns em sua formação. Imersão no estudo do latim, com leitura de textos clássicos, e admiração especial pelas Metamorfoses de Ovídio e Vidas paralelas de Plutarco.

Plutarco, principalmente por intermédio da vida de Júlio César, teria sido o caminho para descobrir a essência da visão trágico-histórica, abandonando o conceito medieval de tragédia como relato da inevitável queda de todo homem que atinge as culminâncias da fama e do poder, por interferência do destino ou da Divina Providência(...) para adotar uma visão trágica do homem responsável por seu destino, que emana, em boa parte, dos atos do indivíduo (HELIODORA, 2005, p. 166).

Tanto em Montaigne quanto em Shakespeare, temos a mente como um labirinto, os processos interiores como enigmas, a recusa de apresentar a solução para os dilemas humanos, para os desafios éticos, amorosos, religiosos ou políticos que trazem. Ao contrário, promovem nova maneira de apresentar a subjetividade com interesse cada vez maior pelo que escapa à razão nos processos interiores ocultos.

Assim, Shakespeare, em seu Hamlet, suprime o motivo da loucura simulada, que era óbvio e necessário na versão medieval. "Extirpando o fundamento da loucura, faz dela o foco central da tragédia. A simulação da loucura parece encobrir algo semelhante à loucura” (GREENBLATT, 2011, p. 314).

Há sempre algo de turvo, de ambíguo, nos processos mentais, nos sentimentos dos protagonistas de suas grandes tragédias. Shakespeare nos ensina que a arte não é lugar para dar respostas, para explicar o homem, mas para inquietar. Radicaliza nesse sentido, eliminado também em 
Otelo, Rei Lear e Macbeth “o elemento explicativo básico, obstruindo desse modo o raciocínio, a motivação ou o princípio ético responsável pela ação que se desenrolaria. A supressão de uma explicação fácil e reconfortante que parecia fazer pleno sentido” (GREENBLATT, 2011, p. 330). A bem da verdade, em Macbeth a ambiguidade não se dá pela supressão do motivo da ação. Diferentemente do desconhecimento da causa da loucura de Hamlet, do ódio de Iago por Otelo, da prova de amor que Lear exige das filhas, aqui o público sabe que Macbeth assassina o rei para ocupar o trono. Mas, aqui, é o próprio protagonista que não se compreende:

Estes meus medos

São menos do que o terror que eu imagino;

Meu pensamento, cujo assassinato

Inda é fantástico, tal modo abala

A minha própria condição de homem,

Que a razão se sufoca em fantasia,

E nada existe, exceto o inexistente.

(...) Escorpiões entopem minha mente, querida!

(SHAKESPEARE, 2010, p. 458, 505).

Por fim, quero trazer dois pensadores que foram emblemáticos para a construção do mundo labirinto, apartando suas muralhas, pela contestação da física aristotélica, solapando as bases científicas com que a escolástica pretendeu alicerçar a teologia cristã. Já foram anteriormente referidos, são eles Giordano Bruno e Galileu Galilei. Seus nomes estão associados a julgamentos e condenações pelo Tribunal do Santo Ofício. Estudamos nos livros de História que, por contrariarem a concepção geocêntrica, foram acusados de heresia. O primeiro foi queimado numa fogueira em Roma, no ano de 1600, e o segundo escapou por pouco, pois negou o heliocentrismo copernicano para não ter o mesmo destino.

Entretanto, não foi bem assim. E aqui entram em cena mais uma vez Epicuro, Lucrécio e um Concílio da Igreja. Dessa vez, o Concílio 
de Trento, em 1551. Nele, foi estabelecido o dogma da Eucaristia, para o qual a hóstia, ao ser consagrada na missa, se torna o corpo de Cristo, assim como o vinho se transforma em seu sangue. A física de Aristóteles, com a distinção entre substância e acidente, permitia explicar a transubstanciação: "como algo com a aparência, o cheiro e o gosto de um pedaço de pão podia de fato (e não meramente num nível simbólico) ser a carne de Cristo. O que os sentidos humanos percebiam eram apenas os acidentes do pão: a substância da hóstia consagrada era Deus” (GEENBLATT, 2012, p. 211).

A Congregação do Santo Ofício batia (literalmente) pesado nos recalcitrantes. Numa época de grande contestação de pontos fundamentais da doutrina católica por parte dos reformadores protestantes, o materialismo atomista de Epicuro e Lucrécio é tido como um inimigo a ser combatido, pois negava a diferenciação entre substância e acidente, tendo a Sociedade de Jesus proibido a teoria dos átomos.

Entrou para a história que Galileu foi condenado à prisão domiciliar por heliocentrismo. Entretanto, séculos depois (já na década de 1980), o historiador Pietro Redondi desencavou um documento nos arquivos do Santo Ofício, na biblioteca do Vaticano, que mudaria a centralidade de tal motivação para a punição. O manuscrito acusatório fazia referência ao atomismo e trazia à baila Orazio Grassi, jesuíta estudioso de astronomia e que fora alvo dos sarcasmos de Galileu, sob o nome fictício de Lotario Sarsi, no Saggiatori (O Ensaiador). Naquele documento, pergunta-se ao tribunal o que acha das teorias atomistas de Galileu. Redondi reconheceu a letra e o estilo argumentativo daquele que tinha sido vítima de tantas ironias. Em seu livro Galileu herético, sustenta que houve um acordo entre o papa, admirador de Galileu, e os jesuítas para poupá-lo (e a Igreja também) da fogueira. Se Galileu fosse condenado por heresia contra o dogma da Eucaristia, não haveria como salvá-lo. A condenação pelo heliocentrismo copernicano era a resposta a uma transgressão considerada menor e que poderia poupar a vida do homem de ciência mais notável da época. Para Italo Calvino (2015, p. 295), que 
escreveu sobre o livro de Redondi, “a questão cosmológica no século XVII era secundária, ao passo que uma questão que hoje nos pareceria passível de ser considerada apenas no plano simbólico espiritual era de uma relevância científica primária”. E toda interpretação simbólica era chamada de "nominalista” e acusada de heresia.

Metáforas, especialmente as fundantes de concepções religiosas, patrióticas, políticas, causam efeitos imensos no mundo real. Como vimos, por elas se mata e se morre.

\section{Referências}

BORGES, Jorge Luis. A muralha e os livros. In: BORGES, Jorge Luis. Obras completas. Volume II (1952-1972). São Paulo: Globo, 2005.

CALVINO, Italo; REDONDI, Pietro, Galileu Herético. In: CALVINO, Italo. Mundo escrito e mundo não escrito. São Paulo: Companhia das Letras, 2015.

CARO, Tito Lucrécio. Da natureza: Epicuro, Lucrécio, Cícero, Sêneca, Marco Aurélio. São Paulo: Abril Cultural, 1973 (Os Pensadores).

ECO, Umberto. O nome da rosa. Rio de Janeiro: Nova Fronteira, 1992. . Da árvore ao labirinto. Rio de Janeiro: Record, 2013.

EPICURO. Antologia de textos de Epicuro. In: . Epicuro, Lucrécio, Cícero, Sêneca, Marco Aurélio. São Paulo: Abril Cultural, 1973(Os Pensadores).

. Carta sobre a felicidade (a Meneceu). São Paulo: UNESP, 2002.

GLEISER, Marcelo. Criação (im)perfeita. Rio de Janeiro: Record. 2010.

GREENBLATT, Stephen. Como Shakespeare se tornou Shakespeare. São Paulo: Companhia das Letras, 2011. 
. A virada: o nascimento do mundo moderno. São Paulo: Companhia das Letras, 2012.

HELIODORA, Barbara. O homem político em Shakespeare. Rio de Janeiro: Agir, 2005.

LEMGRUBER, Márcio Silveira; OLIVEIRA, Renato José. Argumentação e educação: da ágora às nuvens. In: LEMGRUBER, Márcio Silveira; OLIVEIRA, Renato José. (Org.). Teoria da argumentação e educação. Juiz de Fora: UFJF, 2011.

MONTAIGNE, Michel. Ensaios. v. 1. Tradução de Sérgio Milliet. São Paulo: Nova Cultural, 1996 (Os Pensadores).

PERELMAN, Chaïm. Analogia e metáfora. In: . Enciclopédia Einaudi. v. 11. Lisboa: Imprensa Nacional/Casa da Moeda, 1987, p. 207-217.

. Retóricas. Tradução Maria Ermantina Galvão G. Pereira. São Paulo: Martins Fontes, 1997.

PESSANHA, José Américo Motta. As delícias do jardim. Disponível em: <https://docs.google.com/file/d/0B0T4Yj74aNkkejNIVHQ5WGZjX1k/edit>. Acesso em: 13 abr. 2015.

RABELAIS, François. Gargântua e Pantagruel. Belo Horizonte: Itatiaia, 2009.

SHAKESPEARE, William. Macbeth. Tradução de Barbara Heliodora. São Paulo: Abril, 2010.

Data de registro: 31/10/2015

Data de aceite: 23/03/2016 